\title{
PROFERINDO QUILOMBO: CANTOS ÉPICOS LATINO-AMERICANOS DE DESCOLONIZAÇÃO E LIBERDADE
}

\section{UTTERING QUILOMBO: AFRO-LATIN-AMERICAN EPIC SONGS OF DECOLONIZATION AND FREEDOM}

\section{Paula Cristina Vilas ${ }^{1}$}

\begin{abstract}
Resumo: $\mathrm{O}$ artigo apresenta uma escuta de três obras - produções artístico-culturais brasileiras da segunda metade do século XX (Teatro Experimental do Negro fundado por Abdias do Nascimento, editor do jornal Quilombo na década de 1950; o filme Ôrí dirigido por Raquel Gerber com textos e locução da historiadora Beatriz Nascimento, nos finais dos 70; e a Missa dos Quilombos de Pedro Casaldáliga, Pedro Tierra e Milton Nascimento, de 1981), com o intuito de embasar uma dimensão filosófica e mitopoética da noção de Quilombo.
\end{abstract}

Palavras-Chave: Quilombo, Palavra-força, Quilombismo, Cultura afro-brasileira.

Abstract: This article presents a listening of three works - Brazilian cultural-artistic productions of the XX Century's second half (the Black Experimental Theatre created by Abdias do Nascimento, editor of the journal Quilombo in the 1950's; the film Ôrí, directed by Raquel Gerber, with texts and locution by the historian Beatriz Nascimento, ends of the 1970's; the Missa dos Quilombos - Maroons' Mass - by Pedro Casaldáliga, Pedro Tierra and Milton Nascimento, 1981) - with the purpose of sustaining a philosophical and mythopoetical dimension about the notion of Quilombo - the Afro-Brazilian Maroons - in Brazil.

Keywords: Quilombo, Strength-word, Maroons, Afro-Brazilian culture.

1 Doutora em Artes Cênicas pela Universidade Federal da Bahia (UFBA). Professora e pesquisadora do Instituto de Investigación en Etnomusicología, Buenos Aires, Argentina. Agradeço ao Prof. Ari Lima o convite para a publicação, por ter me transmitido seu amor pelo pensamento de Beatriz Nascimento, assim como sua palavra sempre sensível e lúcida. Agradeço ao meu amado esposo e companheiro Luis Ferreira Makl pela sua presença e apoio constantes. 
Esse texto busca comunicar e compartilhar uma escuta possível, entre tantas outras, de vozes que enunciam poeticamente, cantam, narram e proferem uma palavra poética nomeando e outorgando sentidos e múltiplas dimensões a noção de quilombo; por isso é uma escuta, mais do que uma leitura, de três obras que giram e nutrem tais sentidos: o Teatro Experimental do Negro fundado por Abdias do Nascimento, editor do jornal Quilombo na década de 1950; o filme Ôrí dirigido por Raquel Gerber com textos e locução da historiadora Beatriz Nascimento nos finais dos anos 1970; e a Missa dos Quilombos de Pedro Casaldáliga, Pedro Tierra e Milton Nascimento de 1981, três produções brasileiras da segunda metade do século XX.

Foram escolhidas com a arbitrariedade do afeto e da comoção, porque fizeram parte do processo de uma pesquisa, porque elas nos impactaram e nos acalentaram e porque essas obras nos encontraram para trazer respostas. $\mathrm{O}$ contato com elas produziram vivências intensas, ainda muito antes de imaginar que o povo brasileiro, com a sua generosidade, outorgaria uma bolsa de pesquisa para que uma mulher socialmente branca, nascida na capital de Argentina, pesquisasse uma comunidade negra rural no interior de Goiás e orientasse pesquisas de estudantes brasileiros de Artes Cênicas, de 1999 a 2003. E que, simultaneamente, ao longo desse período, a comunidade de Pombal, no Município de Santa Rita do Novo Destino, em Goiás, formasse uma Associação de Moradores que solicitou ao Estado Federal o reconhecimento da comunidade como remanescente de quilombo.

Na hora de decidir o local da pesquisa, que se focalizaria nas formas de produção de canto, música e dança, soube do artigo 68 da Constituição da República Federativa do Brasil de 1988 e a possibilidade do direito à titulação e posse da terra a toda comunidade remanescente de quilombo. Desde a nova Constituição, então, algumas comunidades passaram por um processo de reconhecimento e, em algumas oportunidades, se elaboraram laudos antropológicos. Mesmo que atravessado, como todo campo político, por inúmeros conflitos, a possibilidade do reconhecimento da terra tinha peso de lei e abria novas possibilidades ao campo de 
Pontos de Interrogação, v. 3, n. 2, jul./dez. 2013

Revista do Programa de Pós-Graduação em Crítica Cultural

Universidade do Estado da Bahia (UNEB), Campus II - Alagoinhas - BA

uma pesquisa em performance que concebeu ao próprio trabalho de campo como uma performance com implicações políticas.

Portanto, ao longo desses anos, lemos os textos antropológicos com a consciência de que quilombo, como afirma Ilka Boaventura Leite já constituía "um direito a ser reconhecido e não propriamente apenas um passado a ser rememorado". O que precisamos rememorar, como nos adverte Leite, é que para esses quilombos de hoje, sejam de resistência à escravatura ou de outras modalidades (ocupações de terra, heranças, alforrias), o "simples ato de apropriação de um espaço para viver passou a significar um ato de luta, de guerra", já que a partir do contexto histórico da lei de Terras de 1850 se excluiu aos africanos e seus descendentes da categoria de brasileiros, situando-os em uma categoria separada de libertos, status quo que não se modificará após a abolição (LEITE, 2000:2). Os quilombolas tiveram que se tornar invisíveis, simbólica e socialmente, para sobreviver.

As novas pesquisas do final e início do milênio revelavam um imenso Brasil rural negro e faziam surgir inúmeras dificuldades políticas nos processos de reconhecimento e titulação, que excedem os objetivos desse texto. Mas perante tamanha possibilidade de transformação política chamava-nos a atenção que os textos não abordassem os antecedentes políticos da Constituinte que concluíram na inclusão do artigo 68. Começamos a nos perguntar pelos processos políticos que levaram o "quilombo" ao maior espaço republicano que é o órgão que pensa a lei que organiza o país. Com exceção de Boaventura Leite, os textos antropológicos não lembram o papel dos pensadores e ativistas dos movimentos sociais negros que produziram a inclusão da questão quilombola na Assembléia Constituinte.

As pesquisas e laudos significaram o alargamento para o campo sócio-antropológico do conceito de quilombo, até então de domínio histórico, mas para tal processo houve uma agenda política, e tal agenciamento, para além dos nomes que o levaram adiante, foi alimentado por pesquisas, pensamentos e sentidos produzidos pelos intelectuais, pensadores artistas e ativistas dos movimentos sociais negros.

Sintetizando, podemos pensar a noção de quilombo em um continuum como passadopresente-futuro: o passado, o quilombo histórico, sustentado com vasta bibliografia produzida fundamentalmente pelos trabalhos acadêmicos dos historiadores especialmente sobre Palmares (sem esquecer que Edison Carneiro (1946) também dedicou na sua obra um livro ao em- 
blemático quilombo) ainda que, com a exceção de Clóvis Moura (1981), não impactam o imaginário nem conseguem sair dos limites do mundo acadêmico. As etnografias e laudos que dão conta da diversidade cultural dos quilombos ao longo do território brasileiro sustentam a dimensão sócio-antropológica de quilombo com base jurídica constitucional a partir do artigo 68. Mas o futuro, o horizonte é a terceira dimensão filosófica e mitopoética de quilombo, produzida pelo pensamento de muitos homens e mulher o qual as três obras desse texto - acredito que - representam.

Para além da militância racial, tais obras fazem parte, a meu ver, dos cantos épicos da descolonização e liberdade para o continente, para a nossa America Latina ou Nuestraamérica no dizer de José Martí, que busca se produzir a si mesma, superando a colonialidade do poder, percebendo a necessidade de produzirmos símbolos para a descolonização e a liberdade, símbolos que nos contenham e nos ajudem a resolver a dor colonial dos violentos processos da escravidão, conquista e colonização.

$\mathrm{Na}$ época da pesquisa em Pombal, uma vizinha da localidade mais próxima da comunidade, vinculada ao poder político municipal, alarmada pela presença da nossa equipe que se prolongava no tempo e perante os esforços de organização da Associação de Moradores, disse que os pombalinos estavam buscando serem reconhecidos como "descendentes de Colombo"! Não casualmente foi o que compreendeu e conseguiu reproduzir foneticamente ao se deparar com a expressão "remanescente de quilombo", mas no sentido totalmente antagônico porque a descendência de Colombo, como muitos projetos políticos ainda hoje pretendem, só reafirmam a rêmora colonial; enquanto a remanescência de quilombo possibilita o reconhecimento dos direitos fundiários e simbólicos: esse ser escravizado também se "aquilombou”, essa dignidade constitui um verdadeiro antídoto à dor colonial.

Entre os primeiros laudos publicados, encontra-se o Quilombo do Rio das Rãs, dos antropólogos Adolfo Neves de Oliveira e Siglia Zambrotti Doria, com a organização de José Jorge de Carvalho, quem fez o prólogo aos documentos contidos no laudo (dados etnográficos da comunidade e reflexões sobre as práticas periciais) com um capítulo dedicado à experiência histórica dos quilombos nas Américas e no Brasil. Tem sido pouco habitual, lamentavelmente, a contextualização nas Américas para a compreensão dos quilombos no Brasil. Os palenques, os homens e mulheres maroons, as comunidades cimarronas e os cumbes, consti- 
Pontos de Interrogação, v. 3, n. 2, jul./dez. 2013

Revista do Programa de Pós-Graduação em Crítica Cultural

Universidade do Estado da Bahia (UNEB), Campus II - Alagoinhas - BA

tuem experiências de liberdade semelhantes frente ao mesmo sistema opressor, de resistência à escravidão para além das fronteiras de cada estado- nação. Elas abrem a perspectiva em relação à conhecida história do cativeiro negro nas Américas: necessitamos narrar a negada história da rebelião contra esse regime, já que "moldaram profunda e definitivamente, até os dias atuais, o perfil ideológico, cultural e psicossocial de todos os países das Américas negras" (CARVALHO, 1996:14).

Acredito que a intenção de Carvalho, nesse capítulo, é reunir alguns dos mitos mais importantes surgidos na resistência escrava no Novo Mundo - como a narrativa histórica e mitopoética sobre Nanny, rainha dos quilombos, heroína nacional da Jamaica, já abordada por Lélia González (GONZÁLEZ, 1988) - com o fim de sublinhar esses atos de heroísmo e construir uma narrativa contra-hegemônica. Os relatos canônicos apenas dedicam aos africanos o papel de seres que foram escravizados, tornados mercadorias, em contraposição aos indígenas que teriam resistido dignamente, escolhendo até a morte antes de se submeter à escravidão. Perante esse lugar subalternamente indigno, por aceitar a condição da escravidão ou a mansidão doméstica de servidor do lar, assim como o caráter traiçoeiro daqueles que serviram aos senhores traindo aos seus como capitães-do-mato ou feitores, o mapa mítico, traçado por Carvalho, consegue realçar como contraponto o caráter heróico da resistência. Essa escolha não o impede de reconhecer que nas sagas das lutas dos escravizados houve também fracassos, perseguições, retrações, armistícios, traições.

Carvalho reivindica o caráter heróico dos quilombos, questionado por algumas tendências historiográficas pelas ambiguidades frequentemente presentes nas negociações de quilombolas com a sociedade dominante. Argumenta que embora tais ambiguidades tenham existido, torna-se necessário recuperar as "trajetórias libertárias" dos quilombolas e o heroísmo de resistirem à crueldade da escravidão, de terem tido a coragem de fugir e sobreviver e, sobretudo, a capacidade de construção comunitária. Para Carvalho, muitos quilombos hoje são herança de uma vida realmente comunitária, onde há posse coletiva da terra, uma relação integrada com o meio ambiente; emblemas de comunidades como uma utopia de liberdade, fraternidade e autonomia (CARVALHO, 1997:158).

Finalizando essa introdução, compartilho uma questão paradoxal: na Argentina, meu país de origem, o termo "quilombo" é utilizado vulgarmente com um sentido profundamente 
pejorativo, associado historicamente aos bordéis. Atualmente se utiliza como sinônimo de caos ou bagunça; o que possibilita que para alguns jovens seja positivo no sentido de rebeldia: "armó quilombo", "es un quilombero". Particularmente, vivo essa tensão semântica dentro de mim, e me parece ser emblemática, com respeito ao significante tabu, ainda mais do que vazio, que tem sido a herança africana no meu país (ANDREWS, 1990). Então, quilombo é uma chave mestra que nos ajuda a transitar pelos séculos da história da região e nos possibilita pensá-la em novas perspectivas e nos produzirmos em novas claves simbólicas, como tem nos legado os pensadores de Nuestramérica, entre eles as vozes dessas três obras que abordaremos.

\section{ABDIAS DO NASCIMENTO: DO QUILOMBO QUE CONTAVA O "TEN" (TEATRO EXPERIMENTAL DO NEGRO) AO QUILOMBISMO}

Os Movimentos Negros no Brasil reconhecem o Abdias do Nascimento inequivocamente como um referente maior, um nome axial, uma figura paradigmática. O fazer artístico, a produção de palavra, no caso o fazer teatral, tem sido o espaço inaugural da tarefa de Nascimento como ativista político e liderança: o Teatro Experimental do Negro (TEN) criado e dirigido por Abdias de Nascimento, em 1944. Christine Douxami, tal como outros(as) estudiosos(as) do assunto, coloca o empreendimento de Abdias do Nascimento, o TEN, como pioneiro e inaugurador de um espaço que formou os primeiros atores/atrizes e autores negros do teatro brasileiro (DOUXAMI, 2001:313-363).

Anos mais tarde, em 1980, Nascimento formula sua proposta de quilombismo que constitui o ápice de um projeto que começara com a primeira importante realização pública da sua obra, o Teatro Experimental do Negro, a partir de uma radical proposta de ocupação do espaço cênico, o teatro ocidental. Proponho-me a entender que sentidos de quilombo -como épica da liberdade - estão embutidos nessas realizações, desde a criação do TEN até a formulação de uma proposta política - para toda a sociedade - inspirada no espírito libertário dos quilombos. Acredito que a obra de Nascimento pode fornecer pistas, não apenas para a realização de um teatro negro no Brasil, mas como marco de referência que possibilite a discussão e a formulação de propostas para a área da performance, especialmente no contexto da espetacularização das artes performáticas, negras, no Brasil. 
Pontos de Interrogação, v. 3, n. 2, jul./dez. 2013

Revista do Programa de Pós-Graduação em Crítica Cultural

Universidade do Estado da Bahia (UNEB), Campus II - Alagoinhas - BA

Ao publicar em 1960 uma coletânea com a produção dramatúrgica do TEN, os Dramas para Negros (composta por três autores negros e autores brancos como Augusto Boal e Nelson Rodrigues), Nascimento escreve um "Prólogo para Brancos". Nesse prólogo, ele organiza uma exposição que constitui o que hoje entenderíamos por uma aula de estudos da performance, na qual relativiza o conceito de teatro com as ferramentas conceituais da época, obviamente. O prólogo tem um caráter de vanguarda até hoje, acredito, pelo leque temático aberto, que vai desde as "raízes da dramática negro-brasileira" até o "teatro africano" entendido como "o mundo da literatura sem letras", no dizer do estudioso cubano Fernando Ortiz, citado por Nascimento. Esse é o mundo que o autor remete aos vários tipos de narradores africanos, entre eles, o griot. O leque temático segue com o "teatro negro brasileiro" e o "teatro africano" onde são consideradas práticas que hoje chamaríamos performáticas até a produção de cena da época, o "teatro afro-francês", "teatro afro-cubano" e "teatro afro-norte-americano".

A narrativa que já hoje constitui o mito fundacional do TEN, narrada pelo próprio Nascimento (1968) e também pelo seu colega Efraim Tomás Bó (NASCIMENTO, 1966), conta que em Lima, Peru, em 1941, assistiram a uma montagem de O Imperador Jones de Eugene O’Neill. Nascimento teve um profundo impacto emocional ao ver um ator branco pintado de negro. Essa situação motivou sua decisão imediata de abrir no Brasil um espaço de trabalho para atores negros: o TEN, que saiu à luz com a estréia dessa mesma peça, com um ator negro como protagonista, no Teatro Municipal do Rio de Janeiro, na época capital federal do país. Douxami afirma que Abdias do Nascimento conseguiu estrear nesse emblemático espaço porque o denunciou como "fortaleza do racismo" num encontro da classe teatral com o então presidente Getúlio Vargas (DOUXAMI, 2001:318). A própria arquitetura do Teatro Municipal, um faustuoso prédio com colunas com os nomes de Verdi e Goethe, e sua localização no centro da cidade junto ao Museu Nacional de Belas Artes e à Biblioteca Nacional, denota, com transparência, o lugar reservado ao teatro - no seu mais estrito senso de forma européia, com Grécia como mito de origem - no aparato cultural de constituição do país como nação.

Para compreender a relevância da criação do TEN, pode-se recorrer aos estudos de Miriam Garcia Mendes (1993) que argumenta que a personagem negra no teatro brasileiro do século XIX desde a criação de um teatro nacional (1838) até a abolição (1888), tem um lugar degradado e paródico; assim como para o período de 1889 a 1945 a autora chama o negro de persona non grata do teatro brasileiro. Seguidamente, analisa a fundação do TEN e o toma 
como "parâmetro para o estudo" embora realize algumas considerações críticas, sobretudo pelo que considera como uma experiência sem continuidade, posicionamento este discutido por outros autores como Douxami (2001). A Fundação Nacional de Artes Cênicas publicou, em 1988, uma edição especial dedicada ao TEN em que é reivindicado como um espaço de construção de cidadania.

O próprio Nascimento conta que quando o TEN institui, após a sua criação, os cursos de teatro, a maioria dos inscritos era analfabeta. Nascimento lembra que, então, instituíram um curso de alfabetização e outro de iniciação a "cultura geral" lecionado por Agnaldo Camargo, que era advogado e foi o ator que protagonizou Imperador Jones. As duas grandes damas negras da cena brasileira que se formaram no TEN, Ruth de Souza e Lea Garcia, confirmam essa informação e lembram, em textos publicados nessa coletânea, das próprias experiências. Ruth de Souza conta: "trabalhávamos durante o dia e ensaiávamos à noite. Havia gente de todo o tipo - estudantes, empregadas domésticas - e era muito bonito ver toda aquela gente tão interessada". Ambas as atrizes contam que nenhum deles, nem Nascimento, tinham estudado teatro, mas que Nascimento buscava profissionais que contribuíssem à formação dos atores. Lea Garcia considera que a partir do TEN "começávamos a adquirir consciência negra através do trabalho para o que Nascimento a 'despertava'." Segundo a atriz, a exclusão do negro da cena foi uma realidade na sua trajetória e exemplifica que na época, 1988, estava realizando sua $6^{\mathrm{a}}$ novela como "escrava, já que os atores negros eram convocados apenas para novelas de época, nas quais os quilombolas, se apareciam, o fariam no papel de criminosos fujões"; ou, como continua Lea Garcia, "restando apenas os papéis de doméstica, empregado, prostituta e bandido" (MULLER, 1988:125;136-137).

Essa busca de melhorar as condições de vida para a população negra, a promoção de cidadania e mobilidade social, assim como a ocupação do palco do teatro acredito que outorga ao TEN a dimensão épica e mítica de quilombo, no sentido de tentar superar a condição da escravidão. Não casualmente, Nascimento batizou o primeiro órgão de difusão de suas idéias, o jornal publicado entre 1948 e 1950, como Quilombo. Muitos anos depois, em 1980, Abdias no Nascimento publica, no Brasil, $O$ Quilombismo, composto de seis "documentos" que são estudos publicados anteriormente fora do Brasil; o último é dedicado aos seus "irmãos negros no Brasil" e nele o pensador desenvolve o conceito de quilombismo como um "emergente do 
Pontos de Interrogação, v. 3, n. 2, jul./dez. 2013

Revista do Programa de Pós-Graduação em Crítica Cultural

Universidade do Estado da Bahia (UNEB), Campus II - Alagoinhas - BA

processo histórico cultural" da presença da população negra no Brasil (NASCIMENTO, 1980:245).

O Quilombismo lança uma proposta inspirada nos quilombos históricos compreendidos como espaços comunitários que, além de resgatar sua liberdade e dignidade através da fuga do cativeiro, se dedicam à organização de uma sociedade livre. Assim, para Abdias do Nascimento, quilombo supõe formas associativas que tanto podem estar localizadas no meio de "florestas" de difícil acesso - o que facilitava sua defesa e organização econômico-social própria - como também podem assumir modelos de organização permitidos ou tolerados pela ordem hegemônica com finalidades religiosas, recreativas, esportivas, culturais ou de auxílio mútuo. Segundo o autor, todas elas tiveram e tem uma importante função social na continuidade da cultura africana, o que leva Nascimento a compreendê-los como "genuínos focos de resistência cultural". Desse modo, a rede de associações, terreiros, centros, irmandades, confrarias, grêmios, tendas, afoxés, escolas de samba, gafieiras foram e são "quilombos legalizados pela sociedade dominante" (NASCIMENTO, 1980:255-257).

Segundo o autor, tanto os quilombos permitidos como os "ilegais" constituem uma única afirmação humana, cultural e étnico-racial perante a constituição do Brasil como estadonação. A essa "práxis afro-brasileira", a esse complexo de associações, Nascimento denomina Quilombismo. O autor frisa o valor dinâmico na estratégia e na tática de sobrevivência das comunidades de origem africana e destaca seu apelo psicossocial, cujas raízes estão entranhadas na história, cultura e vivência dos afro-brasileiros. O autor cita a historiadora Beatriz Nascimento, importante voz na década de 1980, para quem o quilombo teve um papel fundamental na consciência histórica dos negros.

Acredito importante compreender o TEN como projeto ético-estético nos termos de $\mathrm{Ab}$ dias do Nascimento (1961) além de sociorracial: esse duplo pertencimento está manifesto no texto escrito em 1966, em que Nascimento cita tanto o sociólogo Florestan Fernandes, quanto o dramaturgo e teórico Bertolt Brecht. Do primeiro reivindica que, após a abolição, mantevese inalterada a estrutura econômica e social que excluiu o negro liberto, o que o autor chama da continuidade de uma "escravidão espiritual", e do dramaturgo alemão reivindica o "distanciamento" como estratégia teatral, argumentando ser um recurso propício para a "transformação qualitativa da interação social branca e negra". Assim nasce o TEN com vocação de cena: 
“não interessava ao TEN aumentar o número de monografias" e sim atuar com uma profunda convicção no papel transformador das artes (NASCIMENTO, 1966:123).

Em 2003 foram lançados, em edição fac-similar, os jornais Quilombo: Vida, problema e aspirações do Negro, publicados com a direção de Abdias do Nascimento de dezembro de 1948 a julho de 1950, em plena atividade do TEN. Essa possivelmente foi a primeira vez que, ultrapassando as barreiras da historiografia, o termo "quilombo" virava um conceito de afirmação, capaz de fazer um contraponto ao conceito de escravo. No editorial, Nascimento cita Caio Prado Junior: "o negro ganhou sua liberdade não por filantropia ou bondade dos brancos, mas por sua própria luta e pela insubsistência do sistema escravocrata" (NASCIMENTO, 2003:19). Não surpreende que o criador do TEN tenha oferecido em destaque principal da primeira página da primeira edição uma matéria chamada "Há preconceito de cor no teatro?" com uma entrevista ao dramaturgo Nelson Rodrigues, que já tinha escrito, a pedido do TEN, a peça Anjo Negro (RODRIGUES, 1981).

Resulta inexplicável que, ainda hoje, em alguns âmbitos do meio teatral leia-se a peça olvidando que a questão racial é o eixo central do drama. Nelson Rodrigues foi consultado a respeito do motivo ao qual atribuía o afastamento do negro ou mestiço dos palcos brasileiros. Rodrigues respondeu que tinha certeza se tratar de uma "pura e simples questão de desprezo", fazendo alusão ao "branco pintado", o recurso de pintar um ator branco de negro. Rodrigues reivindicava o TEN como um espaço para os atores negros e já denunciava o modelo que ainda é vigente hoje, especialmente na teledramaturgia no Brasil - embora haja alguns escassos sinais de mudanças -, que relega a atores negros os papéis de carregadores de bandeja ou "moleques gaiatos". Para Rodrigues, subestimava-se "a capacidade emocional do negro, o seu ímpeto dramático, a sua força lírica e tudo que ele possa ter de sentimento trágico", e o autor também chamava atenção para a necessidade de que alguma dramaturgia conseguisse "transformar o negro em herói” (NASCIMENTO, 2003:19).

Escrever sobre o TEN e sobre o fundamental papel das Artes na trajetória de Abdias do Nascimento demandaria um fôlego que extrapola os objetivos desse texto. Contudo, gostaria de destacar um aspecto do trabalho do TEN que acredito não ter recebido ainda os estudos e consideração que merece que é a experiência de Psicodrama desenvolvida pelo sociólogo Guerreiro Ramos. Resulta ainda hoje uma atitude de vanguarda por parte do parceiro e colega 
Pontos de Interrogação, v. 3, n. 2, jul./dez. 2013

Revista do Programa de Pós-Graduação em Crítica Cultural

Universidade do Estado da Bahia (UNEB), Campus II - Alagoinhas - BA

de Nascimento a abertura do Seminário de Grupoterapia, realizando experiências psicodramáticas para o "estudo e terapêutica das tensões emocionais do negro" (NASCIMENTO, 1966), experiência que abriu os primeiros passos do Psicodrama no Brasil.

Essa prática estava profundamente vinculada ao projeto ético-estético do TEN: "almejamos a transformação da realidade adversa sem o recurso da truculência, sem a radicalização do ódio" diz Guerreiro Ramos, e segue: "um dia a Negritude não terá mais razão de existência: morrerá para ceder lugar a outro tipo de relações humanas”. Porém, conclui, enquanto isso não acontecer, a Negritude terá que continuar ativa para dar alternativa à população negra, enquanto ela seja apenas "mero objeto de versões de cuja elaboração não participa" (NASCIMENTO, 1966:82-83). Guerreiro Ramos toma como ponto de partida o pensamento e a prática do criador do psicodrama, Jacob Levi Moreno, e expõe, nas matérias publicadas em edições do Quilombo, os princípios dessa prática.

Guerreiro Ramos foi um entusiasmado parceiro de Abdias do Nascimento, embora ele mesmo manifeste que durante os primeiros anos não conseguisse entender sua proposta. Só mais tarde conseguiu "enxergar a intuição" de Nascimento e decide se tornar um aliado (NASCIMENTO, 1966: 82-83). Guerreiro Ramos percebia, naquele tempo, que em apenas sessenta anos de liberdade a população negra estava afetada psicologicamente, que essa população precisava aprender os estilos das "classes dominantes". Para Guerreiro Ramos, o TEN era um campo de polarização psicológica e por isso se propôs a coordenar práticas de Sociodrama e Psicodrama no "Seminário de Grupoterapia do Instituto Nacional do Negro". Vários de seus artigos no Quilombo relatam algumas situações do funcionamento desse seminário em que se evidencia que o racismo era abordado a partir de múltiplas perspectivas, como a dificuldade empregatícia e as relações inter-raciais.

Guerreiro Ramos reconhecia que a população negra tinha se organizado através de formas tradicionais como os terreiros, escolas de samba, porém considerava que esses espaços não passavam de "sobrevivências" prendidas nas matrizes culturais africanas. Não há dúvida de que esse posicionamento, ainda nessa época, era altamente questionável à luz dos estudos de folcloristas e antropólogos. Contudo, os estudos destes, embora legitimassem estética e culturalmente as práticas tradicionais, não conseguiam ultrapassar a barreira tantas vezes denunciada por Nascimento de ver "o negro como objeto de estudos", incorporando suas práti- 
cas à cultura nacional, retificando o status quo, sem promover nenhum tipo de transformação social. Apesar desse aspecto evolucionista e eurocêntrico das idéias de Guerreiro Ramos, parece-me que seu labor é reivindicável quando compreende e colabora com Nascimento para que a população negra conheça os estilos de comportamento da classe média e da sociedade brasileira a fim de alcançar a mobilidade social. "O sociodrama é, precisamente, um método de eliminação de preconceito, ou de estereotipias, que objetiva libertar a consciência do indivíduo da pressão social” (NASCIMENTO, 2003:91).

O interesse aqui é apenas sublinhar que há mais de cinquenta anos Abdias do Nascimento e seu colaborador Guerreiro Ramos, nas páginas do Quilombo e nas práticas do TEN, frisavam a necessidade de aberturas de espaços de práticas concretas onde esses homens e mulheres tivessem voz, pudessem ouvir e reconhecer suas vozes, vozes essas compreendidas a partir da dimensão psicossocial desde a noção de corpo do Psicodrama, pioneira para a época. Acredito que essa dimensão de teatro aplicado, inclusive apesar do trabalho de Augusto Boal ser conhecida e reconhecida internacionalmente, ainda não conta com profissionais e espaços de trabalho suficientes para as necessidades da sociedade brasileira.

Obviamente, não cheguei a ver o TEN em cena e desconheço se existem filmagens e o encontro com as edições dos jornais Quilombo foram uma leitura; mas a voz do TEN vibra e está viva toda vez que um grupo de atores faz alguma leitura dramática ou monta algumas das suas peças, ou ainda quando novos grupos do teatro negro como o vigoroso Bando de Teatro Olodum da Bahia ou a Cia dos Comuns, entre outros, tomam o legado e produzem criativa e corajosamente os novos aquilombamentos que os novos tempos demandam.

\section{BEATRIZ NASCIMENTO: UMA MULHER EM BUSCA DO QUILOMBO}

Beatriz Nascimento realizou, junto com a cineasta Raquel Gerber, um filme longa metragem, estreado em 1989 após longos anos de pesquisa e trabalho, chamado Ôrí que constitui o testamento de Beatriz Nascimento, mulher negra e nordestina, militante do movimento social negro, pesquisadora, historiadora de formação: suas reflexões filosóficas e sua capacidade poética constituem um todo inextrincável. O valor documental do filme é indiscutível e inclusive seu valor histórico, como das cenas da Quinzena do Negro na USP em 1977 do Movimento Negro, ou das performances negras na cidade de São Paulo, como a escola de samba, o 
Pontos de Interrogação, v. 3, n. 2, jul./dez. 2013

Revista do Programa de Pós-Graduação em Crítica Cultural

Universidade do Estado da Bahia (UNEB), Campus II - Alagoinhas - BA

baile funk. Mas o objetivo do filme é outro, não apenas documentar. Mergulhamos nesses espaços acompanhadas(os) pelo olhar e a voz de Beatriz Nascimento, e o mérito de Gerber foi ter registrado essa voz e esse olhar no turbilhão da produção de um pensamento feminino que busca se compreender e oferecer vias de compreensão. Como Beatriz Nascimento faleceu ainda nova, acredito que seja esse filme o documento fundamental do seu trabalho, do seu pensamento.

Não tinha sido editado ainda, na época em que assistimos ao filme, o sensível estudo de Alex Ratts sobre obra e trajetória de Beatriz, e mesmo desconhecendo os textos que ela tinha publicado fundamentalmente em meios jornalísticos, é que Ratts os organiza como anexos no livro. Lendo esses textos, percebo que a palavra escrita de Beatriz buscar comunicar, acadêmica e politicamente, o que a voz dela no filme vai costurando e tecendo. Sua voz íntima e cálida compartilha, com coragem e confiança no espectador-ouvinte, os meandros criativos do seu pensamento. Os textos confirmam que Ôrí é o périplo de uma mulher em busca de si mesma, uma mulher produzindo sua identidade, que passou duas décadas tecendo o quilombo como "símbolo", como "sede interior e exterior" (RATTS, 2007:123-4).

Beatriz Nascimento assume a voz narradora e poética no filme, vai tecendo suas reflexões, suas percepções desses múltiplos locais pelos quais "viaja". Sua voz não ilustra nem explica; é uma cálida e íntima voz que vai compartilhando o processo de criação do pensamento e, sem receios e pudores, vai revelando como esses pensamentos se elaboram, a partir do que sente, do que vê, do que vive, do que viveu. A grande protagonista do filme é a sua voz. Tomamos contato com a sua imagem poucas vezes (apenas através do mencionado evento da USP ou em algumas fotos antigas da sua infância e juventude) pois é com a sua voz que Beatriz decide compartilhar com seus ouvintes-espectadores, para deixar testemunho do que ela fez consigo mesma ou, para usar uma expressão da também militante negra brasileira Lélia Gonzalez, de como ela veio a se tornar uma mulher negra no Brasil. É sua voz pausada e seu tom íntimo e confessional que nos aproximam dela mesma.

Com imagens aéreas das ondas do Atlântico, em plano zenital, a narradora vai-nos abrindo, com a sua voz, seu mundo numa espiral: desde a sua percepção cósmica até o seu aqui-agora político. Na relação de dois hemisférios entrando em colisão, Beatriz Nascimento fala da África Negra desconhecida que “busca se conhecer através do encontro com quem está 
chegando", e essa África desconhecida não é senão ela mesma. A primeira imagem da África é a emblemática: a "porta do nunca mais" da ilha de Gorée, no Senegal, local de onde foram deportados milhões de homens e mulheres: africanos, negros, escravizados para as Américas.

A opção de Beatriz Nascimento não é pelo retorno a essa África e o projeto de Ôrí fica explícito: a experiência do exílio pressupõe uma perda de imagem e a aventura da narradora é a busca dessa imagem. Imediatamente, em mais uma das tantas ágeis mudanças de imagem que Gerber realiza, em sintonia com o pensamento de Beatriz Nascimento, chocamos com a cidade de São Paulo do século XX: violência policial, denúncias de ato de racismo e a dimensão de resistência em um baile funk e em um salão afro; a narradora diz: "é preciso rosto, é preciso corpo".

Beatriz Nascimento entra, sem receios nem temores, numa reivindicação do quilombo como produção de liberdade no sentido de uma continuidade cultural com a África - e não apenas um reservatório do passado como na visão dos historiadores -, continuidade de criação e recriação mitopoética. Não está em jogo o rigor de uma verdade histórica, mas antes um outorgar sentido; não estão em jogo as memórias da historiografia, mas uma consciência histórica no sentido de uma reconstrução mítica da memória. A partir desse ponto de vista é que se compreende o contraponto entre as imagens do país Dogon, na África, com uma escola de samba que tomou aos Dogon como tema e enredo de carnaval no Brasil; compreendem-se as imagens de uma das primeiras celebrações do Dia da Consciência Negra como data de comemoração a Zumbi dos Palmares, alternativa ao treze de maio; as ruas de São Paulo em continuidade com as imagens da Serra da Barriga, a região arqueológica de Palmares. Imagens que atravessam a floresta, o estar em fuga, migrante, em busca de território; o "estado rebelde de quilombo", no dizer de Beatriz Nascimento: o "quilombo que surge de um homem que reconhece que não é propriedade de outro". Para a narradora, o Brasil abandonado por um Portugal colonizado por Espanha, vira pai de si mesmo em Palmares.

A busca de Beatriz Nascimento não é um mero exercício intelectual e, mais uma vez, ela se coloca a si mesma no centro da cena: imagens próprias, da Beatriz sem rosto, do seu não-corpo, ao formar-se vestindo uma beca e fotos de sua primeira comunhão, com um branco e pomposo traje: "toda a minha vida foi me separar disso", confessa sua voz. Contudo, a sua atitude vocal alarga os sentidos e a tarefa "foi", mas continua. A Beatriz atlântica, históri- 
Pontos de Interrogação, v. 3, n. 2, jul./dez. 2013

Revista do Programa de Pós-Graduação em Crítica Cultural

Universidade do Estado da Bahia (UNEB), Campus II - Alagoinhas - BA

ca, a das encruzilhadas, se pronuncia mais uma vez: "Deus para mim foi sempre uma busca", e as imagens agora são a de uma missa católica num terreiro de Candomblé. A narradora está interessada nas encruzilhadas e nos contrapontos: imagens de terreiro de Candomblé e imagens do baile funk (não do funk carioca, mas dos bailes atualmente conhecidos como "bailes black") ao som da banda Black Rio, em São Paulo, 1980: "entre luzes e som encontro meu corpo aqui", diz a narradora.

A fala de uma mãe de santo explica o ôrí, conceito central do Candomblé para o ritual de incorporação de um membro ao culto; significa "fazer a cabeça", a iniciação a um novo estado de vida, de uma cabeça que se completa nas dimensões do passado, do presente e do futuro; aí explica a escolha do título do filme. A partir do corpo-memória, Beatriz vai ao resgate da dor desse corpo sócio-histórico, da presença da escravidão e do cativeiro no corpo de hoje, e como ela disse "o desejo de não tê-los vivido". Nessa busca não há apenas dor, mas encontro: "o quilombo mítico que minhas mãos tentam alcançar". O desdobramento desse território tem imagens do Jimmy Cliff no Brasil, fazendo ska junto a Gilberto Gil, imagens de discussões e conflitos da militância entre a necessidade de unidade e a realidade da diversidade.

Nesse múltiplo e complexo território vemos emergir pensamento: a árdua construção do comunitário, o quilombo como questão vinculada ao poder, à consciência negra como uma forma de "assumir o conflito e não jogar o ódio da dor de ser discriminado contra si mesmo" como afirma o poeta Cuti, registrado no filme. Por isso, para Beatriz Nascimento, quilombo é núcleo simbólico para construção do corpo comunitário, do corpo físico como memória, do corpo-cabeça como sistema de pensamento. E, extremamente próxima do pensamento de Abdias do Nascimento, os sistemas mítico-simbólicos - os terreiros, as escolas de samba e tantos outros - são entendidos como quilombos "no sentido de nações territoriais míticas pessoais".

O filme é o pensamento mítico-histórico de Beatriz Nascimento, desde a concreta experiência de uma mulher negra, nordestina, sergipana, migrante para a grande cidade do Rio de Janeiro. O filme é a busca do seu corpo desde o seu próprio corpo, sua autoconstrução, suas referências escolhidas. O quilombo é uma história e é um território simbólico em permanente construção, "da luta de libertação do negro, da luta de libertação de si próprio, da luta de libertação do termo negro". "É preciso haver um mito, é preciso haver um herói, é preciso 
saber as falhas do mito e do herói para crescer", ouvimos da narradora, vemos imagens da divindade Ogum em um terreiro e imagens de Abdias do Nascimento com outros militantes de América Latina, em um congresso. ${ }^{2}$

A narradora chega ao fim: durante o tempo que ouvimos seu chamado, na sua voz quase uma prece, soa uma bela música de Naná Vasconcelos; imagens de porta-bandeiras, das filhas de Santo de Iemanjá no mar, das baianas das escolas de samba. A busca do feminino se vincula à dimensão cósmica - a terra como Ilê (casa sagrada), a energia da terra captada pelo corpo. Imagens de guerras, da bomba atômica, a terra ameaçada: "à terra foi dado um novo ciclo de vida, mulher do planeta mulher, terra mãe atômica de um corpo celestial". A narradora faz dizer a historiadora: "a história que eu idealizo é uma história continente, como as paredes de um útero". Rostos de mulheres negras, no Brasil, na África; saias rodando, baianas rodando, porta-bandeiras rodando. Sinto a dimensão do sentido da vida vinculada à terra que o seu Ôrí despertou. Nanã, a terra, doadora da vida, vida que devolve à terra o que de lá saiu, assim como a busca da sua própria palavra: "eu queria falar da lua, mas eu não sou silenciosa e plena de luz como só ela sabe ser”. Mas na sua voz de mulher, a narradora Beatriz Nascimento consegue a luz da poesia, por isso me permito transcrever o trecho final da obra da voz como um texto poético:

Para ti, comandante das armas de Palmares, filho, irmão, pai de uma nação, o que nos deste?

Uma lenda?

Uma história?

Um destino?

Ó rei de Angola Jaga, último guerreiro palmar eu o vi, Zumbi, nos passos e nas migrações diversas de teus descendentes, te vi adolescente sem cabeça, sem rosto, com os dedos da história, eu te vi uma mulher em busca de um Ôrí.

Te verei vagando, ó estrela meiga,

${ }^{2}$ O 3ro. Congresso da Cultura Negra nas Américas, São Paulo, 1982. 
ó luz que ainda eu tenho no meu coração,

na minha palma da mão.

Desde aqui eu te espero na minha esperança, no tempo que há de vir.

\section{MILTON NASCIMENTO: UM CANTOR DA MISSA DOS QUILOMBOS}

A Missa dos Quilombos ${ }^{3}$ composta pelos poetas Pedro Casaldáliga e Pedro Tierra com música de Milton Nascimento, gravada em 1982, foi a nossa primeira porta de entrada para perceber essa dimensão mítica do quilombo. Por causa da distribuição internacional das companhias discográficas, conheci esse disco ainda na década de 1980 em Buenos Aires. Na saída da ditadura, os nomes de Dom Pedro Casaldáliga, Dom Helder Câmara, assim como os livros de Leonardo Boff, de Frei Betto e do próprio Paulo Freire apontavam, para a minha geração, outra forma de compreender a dimensão cristã, apontavam caminhos para a América.

A Missa dos Quilombos foi celebrada pela primeira vez em 1981, a céu aberto, na mesma praça da cidade de Recife onde foi exposta a cabeça de Zumbi dos Palmares. Foi celebrada por Dom José Maria Pires, Arcebispo de João Pessoa, conhecido por alguns como Dom Pelé e reivindicado como Dom Zumbi. Dom José Maria escreve uma carta "aos seus irmãos pretos" no encarte do disco, os convoca a recolher os frutos do sangue do Zumbi, dos mártires negros. Nessa longa carta questiona sua própria igreja, chama atenção para o racismo, reivindica os Orixás, as Irmandades de Senhora do Rosário, a rebelião quilombola, a força não só da resistência, mas da construção comunitária.

Pedro Casaldáliga e Pedro Tierra já tinham composto com o músico argentino Martin Coplas, três anos antes, a Missa da Terra Sem Males com o propósito de pedido de perdão aos povos indígenas pelo processo de evangelização colonial. Inscrita na mesma saga, os poetas convocam o músico Milton Nascimento para a composição de uma nova missa, animada por um pedido de perdão aos povos negros pela conivência da Igreja Católica com a escravidão. Sabemos que Dom Pedro escolheu Milton Nascimento para musicalizar a obra. Pedro Tierra

\footnotetext{
${ }^{3}$ Original gravado ao vivo na Igreja de N.S. Mãe dos Homens, Caraça, MG, em março de 1982. Reeditado em CD (NASCIMENTO, CASALDÁLIGA, TIERRA 1995). Não se aborda nesse texto a versão teatral produzida por Luis Fernando Lobo e a Cia Ensaio Aberto em 2002, inclusive por diferirmos profundamente na compreensão da obra, já que a montagem que descaracterizou o sentido sagrado da Missa como celebração foi produzida compreendo a Missa como uma obra que aborda "a exclusão social na sociedade moderna" se afastando do sentido primeiro do quilombo e da explícita homenagem à negritude que tem a obra.
} 
conta que partiu em sua busca e que, quando o achou, descobriu que Milton também estava à procura de Dom Pedro. Acreditamos que a obra artística, que a Missa constitui, vibra em uma sintonia de afinidade com os Congados de Minas Gerais dos quais Milton Nascimento muito aprendeu, mas que, ao que parece, nem sempre reconheceu. Em ocasião de um encontro em $2000,{ }^{4}$ os congadeiros protestaram por músicas tradicionais que teriam aparecido como de autoria de Milton Nascimento quando, segundo eles, são das comunidades. Ainda assim, acredito que a contribuição musical de Nascimento como cantor e compositor é basilar, seu canto outorga uma dimensão poética à obra que, certamente, sem ele não seria a mesma.

A respeito do pedido de perdão, em palavras de Dom Pedro Casaldáliga: "para escândalo de muitos fariseus e para o alívio de muitos arrependidos, a Missa dos Quilombos confessa, diante de Deus e da História, essa máxima culpa cristã”. No entanto, essa confissão não é admitida oficialmente pela Igreja e acarreta mais tarde a proibição da Missa pelo Vaticano, o que motivou algumas apresentações sem celebração, nem consagração do pão.

Acredito que a Missa dos Quilombos é uma obra emblemática para delinear um mapa possível da abordagem mítico-filosófica de quilombo; estimo que se trata de uma potente obra artística com relevância política e forte teor espiritual. É uma produção inter-racial: a voz de um poeta branco de origem europeia, bispo amazônico da Igreja Católica que também garante na obra sua estrutura litúrgica, a voz do outro poeta, brasileiro do Tocantins e a voz cantora de Milton Nascimento, músico negro de Minas Gerais. A obra se inscreve nas produções da Teologia da Libertação, teologia latino-americana da qual Dom Pedro Casaldáliga é um importante representante e que, através das CEBs, Comunidades Eclesiásticas de Base, gerou no Brasil um dos mais importantes movimentos sociais, o Movimento dos Trabalhadores e Trabalhadoras Rurais Sem Terra, MST. Contudo, acredito que a temperatura artística e, ao mesmo tempo, a relevância místico-espiritual da obra, não ficaram diluídas nem no discurso histórico, nem no apelo político, como aconteceu, às vezes, à própria Teologia da Libertação, segundo seus críticos.

A Missa dos Quilombos, assim como a Missa da Terra sem Males, pretendem compreender as mazelas do Novo Mundo desde seus alicerces civilizatórios. Dom Pedro Casaldáliga,

\footnotetext{
${ }^{4}$ Encontro Internacional de Etnomusicologia: Músicas Africanas e Indígenas em 500 anos (EM/UFMG), Belo Horizonte, 2000.
} 
nascido na Catalunha, optou por não mais pisar na terra europeia e, ao pedir perdão em nome de todos os homens e mulheres brancos cristãos, acredito que retomou a tarefa de Bartolomé de las Casas. Como em toda Missa, sobre a Missa dos Quilombos diz Casaldáliga: "é pascal: celebra a Morte e a Ressurreição do Povo Negro, na Morte e Ressurreição do Cristo”. E esse é o sentido outorgado ao quilombo: ressurreição como vitória sobre a morte, como superação da escravidão. Acredito que a Missa vibra na sintonia da magnânima leitura que os afro-norteamericanos realizam do Antigo Testamento bíblico: a opressão e subjugação do povo de Israel, por parte dos faraós egípcios, como via para cantar e narrar a sua própria opressão e condição de escravos. Uma das escolas de poesia vocal e canto, mais maravilhosas do mundo, os gospels e Negro spirituals surgem nas encruzilhadas dessa experiência colonial.

Assim como se propôs a Teologia da Libertação ao ler a vida, paixão e ressurreição de Jesus de Nazaré desde a experiência dos oprimidos da América Latina, a Missa abre a celebração com a perspectiva redentora de um Quilombo-Páscoa, de um povo que com a experiência histórica de ter feito Palmares, poderá fazer um Palmares pascal:

Em nome de Deus de todos os nomes,

Javé,

Obatalá,

Olorum,

Oió.

Em nome de Deus que a todos os homens nos faz da ternura e do pó.

Em nome do Pai, que fez toda carne, a preta e a branca vermelhas no sangue.

Em nome do Filho, Jesus nosso irmão, que nasceu moreno da raça de Abraão.

Em nome do Espírito Santo, bandeira do canto do negro folião.

Em nome do Deus verdadeiro que amou-nos primeiro sem dividição. 
Em nome dos Três que são um Deus só, Aquele que era, que é, que será.

Em nome do Povo que espera, na graça da Fé, a voz do Xangô,

o Quilombo - Páscoa que o libertará.

Em nome do Povo sempre deportado pelas brancas velas no exílio dos mares; marginalizado nos cais, nas favelas e até nos altares.

Em nome do Povo que fez seus Palmares, que ainda fará Palmares de novo - Palmares, Palmares, Palmares do Povo!!!

Os três poetas, em uma voz, assumindo a autoridade do celebrante que abre o ritual - a Missa - invocam essa divindade também africana, também negra. E o pedido de perdão se anuncia já desde a invocação: as velas brancas exilaram os homens negros, e os marginalizam até hoje, inclusive dos altares católicos, ocupado nessa hora por um negro poeta da voz que realiza a invocação, cantando. O pedido de perdão também se deve à negação da cosmovisão do homem negro da realidade celeste. A Missa não pede perdão apenas por ter negado os deuses dos negros, mas por não ter visto o negro Jesus, no Quilombo Páscoa que celebra, nem a sua negra mãe, a Virgem Maria Aparecida como diz uma das estrofes de Mariama, última canção da Missa a ela dedicada:

Maria Mulata, Maria daquelas (?)

Colônias- favela que foi Nazaré [...] (?)

Encoraja os gritos, acende os olhares, ajunta os escravos em novos Palmares!! 
Para re-inventar um modelo fraterno, aqueles que escravizaram têm que pedir perdão verdadeiro, após ter enxergado no espelho a imagem do horror. O pedido de perdão é formulado pelo horror da carne como mercadoria, da alma-psiquê a quem foi negado um espaço neste mundo, como mostram os fragmentos da música do Ofertório

\author{
A brasa dos ferros lavrou-nos na pele, \\ lavrou-nos na alma, caminhos de cruz. \\ Recusa Olorum o grito, as correntes \\ e a voz do feitor; recebe o lamento, \\ acolhe a revolta dos negros, Senhor! \\ Os pés tolerados na roda de samba, \\ o corpo domado nos ternos do congo, \\ inventam na sombra a nova cadência, \\ Rompendo cadeias, \\ forçando caminhos, \\ ensaiam libertos \\ a marcha do Povo, \\ a festa dos negros, acolhe Olorum!
}

A Missa pede perdão pelo brutal processo que obrigou os africanos a aceitar o Deus da Bíblia. Ela dispõe-se a aprender com aqueles que, por sua sabedoria e altíssima espiritualidade, reconheceram uma faísca divina no Deus do carrasco, Deus daqueles que "sangraram a cruz do batismo". Marcados a ferro pelo escravista e pela cruz da Igreja, são eles os mestres do perdão, e a Missa bem o sabe quando diz: o Espírito Santo vem na "bandeira do negro folião". Assim, coloca a todos os que assim o quiserem, como o Candomblé, como herdeiros do patrimônio simbólico afro-brasileiro, convoca-nos a todos ao quilombo; mas sem negar, entre nós, àqueles que na pele estão marcados com o sinal da negritude no sistema do racismo. Pioneiramente, ainda na própria Teologia da Libertação, a Missa faz esse corte racial.

Convivem na obra uma força ético-estética e uma perspectiva histórica. O recitado da Ladainha, no longo refrão, destaca a presença dos "construtores anônimos da Esperança Negra", linhagem construída por artistas, militantes, testemunhas e santos negros. Realiza-se um verdadeiro culto aos ancestrais, aos quais se pede auxílio, convocando a força para uma luta no estilo "dos mestres da reza e do canto". O recitado inicia-se com uma invocação a Zumbi e atinge um total de vinte e oito nomes, onde se incluem ativistas como Amílcar Cabral e Martin Luther King, fatos históricos, como a revolta dos Malês ou o massacre de Soweto pelo 
apartheid da África do Sul; e por fim, apresenta uma relação de santos católicos que o povo negro fez próprios.

Contudo, não há apropriação indevida. A missa é plurivocal: as vozes negras dos celebrantes, Dom José Maria e do cantor-compositor Milton Nascimento e as vozes dos poetas, socialmente brancos, enunciam um nós que oscila, mas sempre sabemos de qual nós se trata, inclusive quando o nós é o inter-racial. Contudo, claro que finalmente é uma missa católica: enuncia que Palmares é o Sinai, e que Zumbi é o Moisés negro, como Dom Pedro o declara no encarte. Essa operação não reduz o universo simbólico africano nem o seu legado na diáspora, mas tenta legitimá-lo perante uma Igreja que o nega, nem o vê nem o escuta e foi cúmplice do extermínio; uma Igreja frequentada pelas burguesias pós-coloniais locais que continuam essa tarefa e constituem o público alvo da Missa.

A Missa não pretende invadir os espaços sagrados afro-brasileiros nem substituí-los. Pelo contrário, ela se propôs, e acredito que em alguma medida conseguiu, a falar alto nas igrejas católicas, tentando sensibilizar esses fiéis, que hoje reeditam o modelo colonial que continua escravizando ao excluir e marginalizar os afro-descendentes negros. Daí que veio a proibição e a pichação dos cartazes de divulgação na primeira celebração em Recife, com a foice e o martelo, símbolo do comunismo, na suspeita de que a imagem do cartaz, uma negra mão que segurava uma cruz, contivesse essa imagem subliminarmente.

A Missa, tal como os spirituals, abre uma ponte simbólica entre a antiguidade bíblica e os antepassados históricos numa fusão de tempos míticos. Reconhece-se o espaço celeste para aqueles a quem todo espaço foi negado. No espírito da Teologia da Libertação, a esse espaço celeste precisa-se construir o correspondente terrestre.

Vemos na Missa uma obra de fervor e mística cristã e de denúncia histórico-social, e isso resulta altamente relevante, uma vez que a própria Teologia da Libertação já foi suficientemente questionada por negligenciar os aspectos místicos da relação com o sagrado. A Missa consegue produzir vigor político e histórico e, simultaneamente, consumar o mistério da celebração quilombola-pascal. Uma poesia que convida à experiência mística, dá esperança, dá fôlego para se adentrar na dor, tocar nas feridas sem ficar com as mãos cheias do sangue do horror escravocrata, o horror da "carne vendida", porque há horizonte de quilombo ao qual 
chegar. Quilombo do passado e do futuro, assim como as velhas senzalas são claramente reconhecidas nas novas favelas.

Como em todas as ações invocadas, na primeira canção da Missa, Estamos Chegando, os homens e as mulheres negras vêm dispostos à ação - cobrar, gritar, clamar, lutar. Eles vêm sem medo da memória - lembrar, chorar, rezar, criar, louvar - e sem ressentimentos, na transmutação dos sentimentos - amar, dançar, cantar, gingar.

A Missa não pretende batizar homens e mulheres negros, mas pede perdão não só pela conivência com uma das mais degradantes experiências humanas que é a escravidão, como também pela brutalidade do processo evangelizador. Acredito que a Missa vibra em um espírito inter-religioso que não coloniza o outro, mas dele se aproxima para ouvi-lo, não nega a história, a reconhece, e por isso pede perdão.

Embora escrita nos fins da década de 1970 é uma obra vigente porque não carrega a miopia das ideologias das esquerdas a respeito das questões raciais. Não há resquícios da ideologia da democracia racial, nem da fábula das três raças na Missa. O corte é claramente histórico e racial, porém, ela não se subtrai de posições ideológicas e manifesta suas utopias sociais: um mundo para todos, sem apagar nossas diferenças e nossas histórias.

\author{
Saravá, \\ do novo Quilombo de amanhã. \\ Aiê, dessa terra de todos que virá! \\ Aos treze de maio de mil novecentos e oitenta e oito \\ Nos deram apenas decreto em palavras. \\ Mas a Liberdade \\ Vamos conquistá-la
}

Especialmente reconhecida é a potência vocal da homília de Dom Helder Câmara, Arcebispo de Olinda e Recife, em Invocação à Mariama, registro sonoro ímpar, em que sua voz e seu dizer revelam o espírito que animou todo o seu devir:

Mariama, Nossa Senhora Mãe querida,

Nem precisa ir tão longe como no teu hino,

Nem precisa que os ricos saiam de mãos vazias

E os pobres de mãos cheias. 


\author{
Nem pobre nem rico, \\ Basta de escravo de hoje ser senhor de escravos amanhã! \\ Basta de escravos. \\ Um mundo sem senhores e sem escravos, \\ Um mundo de irmãos, \\ De irmãos não só de nome e de mentira, \\ De irmãos de verdade, Mariama
}

A respeito de Dom Helder, Abdias do Nascimento conta que, em 1955, o Teatro Experimental do Negro, a fim de "promover um reexame da concepção estética brasileira", resolveu por sugestão de Guerreiro Ramos abrir um concurso para artistas plásticos brancos e negros, para plasmarem a imagem do Cristo negro. Nascimento conta as reações iradas, indignadas da imprensa, assim como das autoridades da Igreja Católica que viram o concurso como uma "afronta" e se dispunham a dar um "brado de alarma" contra o "descontrole moral" dessa "pedra de escândalo" e motivo de "repulsa". Nascimento conta que o bispo Dom Helder Câmara não só apoiou o concurso, como compareceu no momento de escolher os melhores trabalhos.

Na oportunidade das históricas peregrinações à Serra da Barriga, Alagoas, sítio histórico do Quilombo dos Palmares, para construir o Memorial Zumbi - registrada em um documentário re-editado como o motivo da homenagem aos 90 anos de Abdias - vemos, em 20 de novembro de 1982, Abdias do Nascimento caminhar acompanhando mãe Hilda, fundadora do bloco afro-baiano Ilê Aiyê, até subir no lombo de um burro. Uma vez no alto, Abdias faz uma saudação aos Orixás, com um caráter de celebração, de invocação. Nesse dia, em um depoimento posterior, escutamos o Abdias agradecendo a presença de uma "Igreja Católica Progressista",

que fazendo um mea culpa, um ato de contrição, tenta purgar o pecado que cometeu, não somente endossando a escravidão, não só batizando compulsoriamente os africanos escravizados ainda mesmo nas costas da África, mas também lutando lado a lado nesta luta de reivindicação e resgate da dignidade humana e dos direitos fundamentais do povo negro e indígena. Essa igreja que repudiou o pecado de ter apoiado a escravidão [está presente] na pessoa do nosso querido Dom José Maria Pires e no exemplo para todos nós, na sua coragem na busca da verdade e da liberdade, que é o bispo Dom Pedro Casaldáliga. (2004) 
Pontos de Interrogação, v. 3, n. 2, jul./dez. 2013

Revista do Programa de Pós-Graduação em Crítica Cultural

Universidade do Estado da Bahia (UNEB), Campus II - Alagoinhas - BA

Finalizando a escuta das três obras, posso lembrar-me do sentido da palavra proferir como declarar, proclamar, levar adiante e acredito que as três obras o realizam, inscrevem no nosso coração essa dimensão libertadora do quilombo. Escutamos palavra-canção, palavraprece, palavra sagrada, palavra ritual, palavra de ordem, palavra celebratória. Será suficiente a letra, a letra do papel ou da tela para produzir a palavra-força como falava Amadou Hampaté Bâ (1980)? Torna-se necessária essa palavra-força para que os sentidos de quilombo, não só os contra-hegemônicos, não apenas os antagônicos à ordem dominante, mas os sentidos alternativos, positivos, criadores como os de construção comunitária, como a "busca do próprio rosto", como esperança, o "quilombo-páscoa" na experiência poética e política dessas três vozes cheguem a nós e sejam símbolos vibrantes que nos ajudem a construir Nuestramérica.

Tenho me permitido escrever sobre essas obras porque acredito que deixam um legado para os socialmente negros, os socialmente brancos, a população indígena, para a sociedade brasileira como um todo e para toda a nossa região através da multidimensão da noção de quilombo. Abdias do Nascimento formula o quilombismo pensando na transformação do país; para Beatriz a "mística" do quilombo alimenta os "anseios de liberdade da consciência nacional" e a "busca de aspectos positivos como reforço de uma identidade histórica brasileira" (NASCIMENTO, 2007:122-3). Acreditamos em tais descentramentos do pensamento eurocêntrico, nos esforços descolonizadores para mestiçar nossa mente entendidos como apropriações (tornar próprio) e não expropriações (virar propriedade) dos símbolos do pensamento produzido por homens e mulheres negras.

Há uma dimensão sagrada tanto na Missa como na noção de ôri: o filme nos lembra que para o candomblé todos temos ôri, reconheçamos ou não essa força natural que nos identifica. Beatriz abre seu olhar na sua sensibilidade planetária: "a Terra é o meu quilombo. Meu espaço é o meu quilombo. Onde eu estou, eu estou. Quando eu estou, eu sou”. (NASCIMENTO, 2007:59). Esse descentramento do "ser" para o "estar", constitui mais uma chave para os que aqui estamos, buscando produzir nosso estar em Nuestramérica e querendo tecer nossa identidade no estar aqui.

Reitero a arbitrariedade afetiva com a qual escolhi essas três obras: muito tempo tem passado e muito tem se produzido. Outros muitíssimos exemplos devem ser possíveis e afortunadamente os desconheço, dada a fertilidade da palavra poética. Mas não posso deixar de 
mencionar a obra do poeta gaúcho Oliveira Silveira que propôs, com profunda aceitação, o 20 de novembro como Dia Nacional da Consciência Negra honrando Zumbi. Em uma feliz sincronia, também em novembro, no dia 8, a partir de 2013 na Argentina celebramos o Dia Nacional do Afro Argentino e a Cultura Afro. Foi o fruto de anos de trabalho e militância e a data honra a uma mulher negra argentina, Maria Remedios Del Valle Rosas que lutou corajosamente nas guerras de Independência.

Continuo lembrando quantas escutas realizamos ao longo da pesquisa no 'quilombo', os poetas da Quilomboje, a obra do poeta Edimilson de Almeida Pereira especialmente seu Signo Cimarrón, poesia brasileira em castelhano do Brasil para as Américas, Chico Science e sua Nação Zumbi, o rap de Racionais MC e uma infindável relação; mas, sem dúvida, com um inicial inequívoco: as performances culturais tradicionais que produziram não apenas uma resistência à brutalidade colonial, mas fontes de vitalidade nessas formas de dançar, de cantar, de produzir música, nesse fazer comunitário. Esses territórios de quilombismos em vigência e constante transformação têm o permanente e fértil poder de convocatória aos jovens por serem territórios de liberdade e reposição de símbolos onde se podem produzir mentes, corpos e almas dessa Nuestraamérica.

Gostaria de destacar o que talvez o(a) leitor(a) já percebeu: os cantos épicos como práticas de descolonização e liberdade e ações políticas de reparação aqui rememoradas são as vozes de uma mulher negra poeta e de dois homens negros poetas: três Nascimentos. Como seriam os sobrenomes ou etnônimos das famílias africanas das quais alguma rama da família procedia? Sabemos que o colonizador escravista deu, irônica e perversamente, à população negra sobrenomes vinculados à religião conquistadora: Santos, Anjos, Nascimento. As vozes poéticas dessa mulher e desses dois homens revertem essa ironia perversa e viram, na palavra, verdadeiros nascimentos.

\section{REFERÊNCIAS}

ALMADA, Sandra. Damas Negras - Sucesso, lutas, discriminação. Rio de Janeiro: Mauad, 1995. 
Pontos de Interrogação, v. 3, n. 2, jul./dez. 2013

Revista do Programa de Pós-Graduação em Crítica Cultural

Universidade do Estado da Bahia (UNEB), Campus II - Alagoinhas - BA

ANDRADE BARRETO, Raquel. Enegrecendo o Feminismo ou Feminizando a Raça: Narrativas de Libertação em Angela Davis e Lélia González. Rio de Janeiro: Diss. de Mestrado PUC-Rio de Janeiro, 2005, s/p.

ANDREWS, George Reid, Los afroargentinos de Buenos Aires. Buenos Aires: De la flor, 1989.

ARAÚJO, Emanoel (curad.). Para nunca esquecer: negras memórias / memórias de negros. Rio de Janeiro: Museu Histórico Nacional, 2002.

AUGEL, Moema Parente. A fala identitária: Teatro Afro-Brasileiro hoje. In: Afro-Ásia, (24): 291-323, 2000.

CARNEIRO, Edson. Guerra de los Palmares. México: Fondo de Cultura Económica, 1946.

CARVALHO, José Jorge de. A experiência histórica nas Américas e no Brasil. In: Carvalho, José J. de; Oliveira, Adolfo N. de; Dória, Siglia Z. (org.), O Quilombo do Rio das Rãs - histórias, tradições, lutas. Salvador: EdUfba, 1995, pp.13-73.

DOUXAMI, Christine. Teatro negro: a realidade de um sonho sem sono. In: Afro-Ásia, (2526): 313-363, Salvador, 2001.

GONZALEZ, Lélia. Nanny. In: Humanidades, (17): 23-5, Brasília, UnB, 1988.

HAMPATÉ BÂ, Amadou. A tradição viva. In: Ki-Zerbo, Joseph, História geral da África I. São Paulo: Atica / UNESCO, 1980.

LEITE, Ilka Boaventura. Os quilombos no Brasil: questões conceituais e normativas. Florianópolis: NUER/UFSC, 2000. Hipertexto disponível em (último acesso 12/07/2007): [http://www.cfh.ufsc.br/ nuer/artigos/osquilombos.htm].

MARTINS, Leda Maria. A Cena em Sombras. São Paulo: Ed. Perspectiva, 1995.

MENDES, Miriam Garcia. O negro e o teatro brasileiro (entre 1889 e 1982). São Paulo: Hucitec, 1993.

MOURA, Clóvis. Os Quilombos e a rebelião negra. Sao Paulo: Ed. Brasiliense, 1981.

MULLER, Ricardo Gaspar (org.). Dionysos: Teatro Experimental do Negro. Rio de Janeiro: Fundacen, 1988.

NASCIMENTO, Abdias do. Prólogo para Brancos. In: Nascimento, Abdias do, Dramas para Negros e Prólogo para Brancos: Antologia de Teatro Negro-Brasileiro. Rio de Janeiro: TEN, 1961a.

NASCIMENTO, Abdias do. "Sortilégio". In: NASCIMENTO, Abdias do, Dramas para negros e Prólogo para Brancos - Antologia de Teatro Negro-Brasileiro. Rio de Janeiro: Edição do TEN, $1961 b$.

NASCIMENTO, Abdias do. Dramas para negros e Prólogo para Brancos - Antologia de Teatro Negro-Brasileiro. Rio de Janeiro: Edição do TEN, 1961c.

NASCIMENTO, Abdias do. Teatro Experimental do Negro. Rio de Janeiro: Testemunhos Edições GB, 1966.

NASCIMENTO, Abdias do. Teatro Negro do Brasil: uma experiência sócio racial. In: Revista Civilização Brasileira, Ano IV (2): 193-211, Caderno Especial CB, Rio de Janeiro, jul., 1968. 
NASCIMENTO, Abdias do. Quilombismo: Um conceito científico emergente do processo histórico cultural das massas afro-brasileiras. In: militância pan-africanista. Petrópolis: Vozes, 1980. . O Quilombismo: Documentos de uma

NASCIMENTO, Abdias do. Uma Informação Sobre o Teatro Experimental do Negro. In: Araujo, Emanoel (org.), A mão Afro-Brasileira: significado da contribuição artística e histórica. São Paulo: Fundação Odebrecht, Tenenge, 1988, pp. 356-69.

NASCIMENTO, Abdias do (dir.). Quilombo: vida, problemas e aspirações do negro [Edição fac-similar do jornal]. São Paulo: Fundação de Apoio à Universidade de São Paulo, Ed. 34, 2003.

NASCIMENTO, Beatriz. O conceito de quilombo e a resistência cultural negra. In: Ratts, Alex, Eu sou atlântica. Sobre a trajetória de vida de Beatriz Nascimento. São Paulo: Instituto Kuanza- Imprensa Oficial do Estado de São Paulo, 2007.

RATTS, Alex. Eu sou atlântica. Sobre a trajetória de vida de Beatriz Nascimento. São Paulo: Instituto Kuanza - Imprensa Oficial do Estado de São Paulo, 2007.

RODRIGUES, Nelson. Anjo Negro. In: Rodrigues, Nelson, Teatro Completo. Rio de Janeiro: Nova Fronteira, 1981.

\section{DISCOGRAFIA}

NASCIMENTO, Milton; CASAldÁligA, Pedro; TIERRA, Pedro. Missa dos Quilombos. CD selo Polygram do Brasil, 811 500-2. São Paulo, 1995.

\section{FILMOGRAFIA}

GERBER, Raquel; NASCIMENTO, Beatriz Santos do. Ôri. São Paulo. Produção: Angra Films. Ano: 1989. Tempo de duração: 1h30', português.

NASCIMENTO, Elisa Larkin; DRUMOND, Afonnso. Abdias Nascimento - Parte 1: um Afrobrasileiro no Mundo. Rio de Janeiro. Produção: IPEAFRO. Ano: 2006. Duração: 26’38”.

NASCIMENTO, Elisa Larkin; DRUMOND, Afonnso. Abdias Nascimento - Parte 2: Momentos Políticos. Rio de Janeiro. Produção: IPEAFRO. Ano: 2006. Duração: 31'06”.

NASCIMENTO, Elisa Larkin; DRUMOND, Afonnso. Abdias Nascimento - Parte 3: 90 Anos, Memória Viva. Rio de Janeiro. Produção: IPEAFRO. Ano: 2006. Duração: 23'48'.

Recebido em: 07 de novembro de 2013.

Aprovado em: 04 de dezembro de 2013. 